\title{
Gamma Scanner Conceptual Design Report
}

\author{
K. L. Swinth
}

November 1979

Prepared for

Hanford Engineering

Development Laboratory

under a Related Services Agreement with the U.S. Department of Energy

Contract EY-76-C-06-1830

Pacific Northwest Laboratory

Operated for the U.S. Department of Energy by Battelle Memorial Institute 
NOTICE

This repont was prepared as an account of work sponsored by the United States Government. Neither the United States nor the Department of Energy, nor any of their emplayees, nor any of their contractors, subcontractors, or their employees, makes any warranty. express or implied, or assumes any legal liability or responsibility for the accuracy, completeness or usefulness of any information, apparatus, product or process disclosed, or represents that its use would not infringe privately owned rights.

The views, opinions and conclusions contained in this repont are those of the contractor and do not necessarily represent those of the United States Government or the United States Department of Energy.

\author{
PACIFIC NORTHWEST LABORATORY \\ operated by \\ BATTELLE \\ for the \\ UNITED STATES DEPARTMENT OF ENERCY \\ Under Contract EY-76-C-06-1830
}

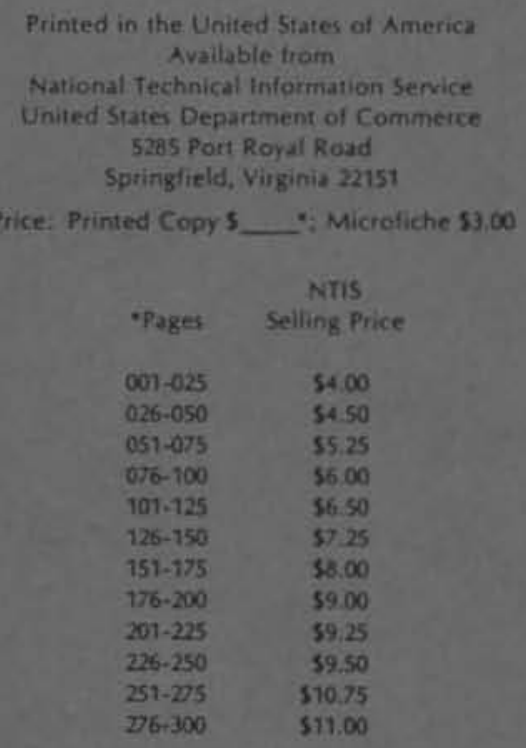


PNL -2758

UC-37

\section{8}

GAMMA SCANNER

CONCEPTUAL DESIGN REPORT

K. L. Swinth

November 1979

Prepared for

Hanford Engineering Development Laboratory under a Related Services Agreement with the U.S. Department of Energy Contract EY-76-C-06-1830

Pacific Northwest Laboratory

Richland, Washington 99352 


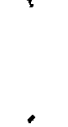

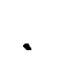




\section{SUMMARY}

The Fuels and Materials Examination Facility (FMEF) will include several stations for the nondestructive examination of irradiated fuels. One of these stations will be the gamma scanner which will be employed to detect gamma radiation from the irradiated fuel pins. This report describes the conceptual design of the gamma scan station.

The gamma scanner will use a Standard Exam Stage (SES) as a positioner and transport mechanism for the fuel pins which it will obtain from a magazine. A pin guide mechanism mounted on the face of the collimator will assure that the fuel pins remain in front of the collimator during scanning. The collimator has remotely adjustable tungsten slits and can be manually rotated to align the slit at various angles. A shielded detector cart located in the operating corridor holds an intrinsic germanium detector and associated sodium-iodide anticoincidence detector. The electronics associated with the counting system consist of standard NIM modules to process the detector signals and a stand-alone multichannel analyzer (MCA) for counting data accumulation. Data from the MCA are bussed to the station computer for analys is and storage on magnetic tape. The station computer controls the collimator, the MCA, a source positioner and the SES through CAMAC-based interface hardware. Most of the electronic hardware is commercially available but some interfaces will require development. Conceptual drawings are included for mechanical hardware that must be designed and fabricated. 


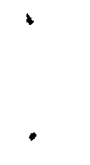




\section{CONTENTS}

\begin{tabular}{|c|c|c|c|c|c|c|c|c|c|c|c|c|}
\hline & & & & & & & & & & & & Page \\
\hline SUMMARY & . & . & . & . & . & . & • & . & . & $\cdot$ & . & $i i j$ \\
\hline FIGURES AND TABLES & - & - & - & • & - & - & $\cdot$ & - & - & • & - & vii \\
\hline INTRODUCTION . & . & . & • & . & . & - & 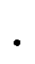 & . & . & 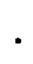 & . & 1 \\
\hline DESIGN REQUIREMENTS & - & - & - & - & - & - & $\bullet$ & - & . & - & - & 2 \\
\hline GENERAL REQUIRE & EMENT & & - & • & - & - & 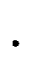 & . & . & - & - & 2 \\
\hline GAMMA SCAN REQL & UIREM & ENTS & - & • & - & - & 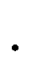 & . & . & - & - & 7 \\
\hline GENERAL DESIGN DESCF & RIPTI & & . & . & . & - & . & . & - & 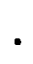 & . & 9 \\
\hline DETAILED DESIGN DESC & CRIPT & ION & - & • & . & - & $\cdot$ & . & . & - & - & 13 \\
\hline PIN HANDLING/PO & OSITI & ONING & SYSTE & & - & - & ${ }^{\circ}$ & . & - & $\cdot$ & - & 13 \\
\hline PIN GUIDE MECHA & ANISM & . & . & . & . & . & $\cdot$ & . & . & 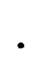 & . & 15 \\
\hline COLLIMATOR & . & . & . & . & . & - & ${ }^{\circ}$ & . & . & 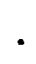 & . & 16 \\
\hline DETECTORS . & - & - & - & - & . & - & ${ }^{\circ}$ & . & . & $\cdot$ & . & 18 \\
\hline GAMMA SCANNER A & ANALO & G ELEC & CTRON & ICS & . & - & $\cdot$ & . & $\cdot$ & $\cdot$ & $\cdot$ & 18 \\
\hline GAMMA SCANNER & DIGIT & $A L$ ELE & ECTROI & NICS & . & - & - & . & . & $\bullet$ & . & 20 \\
\hline CONTROL SYSTEM & ELEC & TRONIC & CS ANL & D COMP & UTER & - & ${ }^{\circ}$ & • & . & $\bullet$ & • & 23 \\
\hline SOFTWARE . & . & . & - & - & - & - & ${ }^{\circ}$ & . & . & $\theta^{\circ}$ & . & 26 \\
\hline SYSTEM CALIBRAT & TION & - & . & . & - & - & 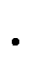 & - & - & $\bullet$ & - & 30 \\
\hline RAPID GAMMA SCA & ANNIN & & . & • & . & . & • & . & - & $\bullet$ & - & 32 \\
\hline SYSTEM RELIABIL & LITY & $\cdot$ & - & - & - & $\cdot$ & - & • & - & - & - & 32 \\
\hline DEDICATED AXIAL & SCA & NNER & - & . & - & . & $\cdot$ & . & - & $\bullet$ & . & 34 \\
\hline APPENDIX . & . & . & . & . & . & - & - & . & . & • & . & 36 \\
\hline
\end{tabular}




\section{FIGURES}

Page

1. Typical Gamma Scan Facility at a Hot Cell . . . . . 3

2. FMEF Nondestructive Examination Hot Cell Work Station Arrangement . . . . . . . . . . . 4

3. Schematic of Standard Examination Stage . . . . . . $\quad 14$

4. System Counting Electronics . . . . . . . . . . 19

5. System Control Electronics . . . . . . . . 24

6. High Count Rate Electronics . . . . . . . . 33

7. Dedicated Axial Scanner Mounted on Cell Wall . . . . . 35

\section{TABLES}

1. Gamma Scanner Analog Electronics . . . . . . . 21

2. Gamma Scanner Digital Signal Processing Equipment . . . . 22

3. Gamma Scanner Control System Items . . . . . . . 25

4. Languages and Operating Systems From Various

5. Types of Data. . . . . . . . . . . . . . . 29

6. Rapid Scanning Electronics . 


\section{INTRODUCTION}

Gamma scanning is the point by point measurement of the gamma activity from a radioactive object. The term is generally applied to the incremental measurement of the activity in an irradiated fuel rod or fuel bundle. The term is most generally applied to the measurement of the activity at discrete points along the axis of a fuel rod or a fuel bundle.

Gamma scanning is performed for two general objectives; one being neutronic measurements on the fuel, the other being metallurgical measurements on the fuel and cladding. Neutronic measurements are related to the power history of the rod or bundle and are used for such things as qualification of neutronic calculation codes, burnup measurements and examination of the power distribution. The metallurgical measurements will measure fuel conditions for such things as fuel integrity, detailed examination of defective zones in fuel, fuel swelling or densification. New techniques permit the measurement of cross-sectional distribution of fission products in the fuel.

The short half-life isotopes such as ${ }^{140}$ La can be used to measure the power distribution in a reactor, while a long half-life isotope $\left({ }^{137} \mathrm{Cs}\right)$ will give information on total fuel burnup. Gaseous or volatile fission products can be used to give an idea of the fuel condition and the cladding integrity.

The major purpose of the FMEF gamma scan facility will be the investigation of the metallurgical properties of FFTF fuels. The fission products in a fuel pin migrate both axially and radially at rates depending on their chemical state and the operating conditions of the fuel pin. Fuel cladding chemical interaction and the thermal and mechanical performance of fuel is impacted by the distribution of the various fission products. Because of this it is important to obtain information on the axial and radial distributions of fission products for correlation with measurements of cladding diameters, cladding loss from fission product attack and fuel thermal performance factors. Gamma scanning prior to destructive examination is a method for obtaining the fission product distribution. 
Gamma scanning can differ in sophistication from a simple manual system to a highly automated system with software control. Most gamma scanners have several pieces of hardware which are common al though the exact implementation of the hardware can differ greatly. Figure 1 illustrates a typical gamma scan facility in a hot cell. The in-cell hardware consists of a scan frame to accurately move the fuel pin and select discrete points for analys is and a pin guide to keep the fuel pin centered on the collimator. Traversing the shielding wall of the hot cell is a collimator which has apertures that select the size of the region on the pin from which gamma activity will be counted. Outside the cell and positioned with respect to the collimator is the detector or detectors which count the activity from the fuel pins. The detectors convert the radiation energy to electrical signals which are cabled to the counting electronics where they are digitized and stored in a format or formats useful to the operator. Another group of electronics outside the hot cell controls the position of the scan frame, and thus, the position of the pin with respect to the collimator. On the more sophisticated systems the computer is used to link the position control electronics and the counting electronics plus perform data analysis.

A11 of the more sophisticated gamma scan installations require specialized software to control the system and perform some of the data analysis. The larger gamma scan systems and installations use a small computer for control of the data collection with storage of the data on magnetic tape. The magnetic tapes are then sent to a large central computer for full analyses.

\section{DESIGN REQUIREMENTS}

\section{GENERAL REQUIREMENTS}

The FMEF is designed to receive fuel from the FFTF for nondestructive and destructive examinations and to characterize and retrieve data from both breeched and unbreeched fuels. The facility will also be able to handle other irradiated components and fuel pins from other facilities. This report is concerned only with a single examination station in the nondestructive examination cell (NDE) which is illustrated in Figure 2. The NDE cell is organized 


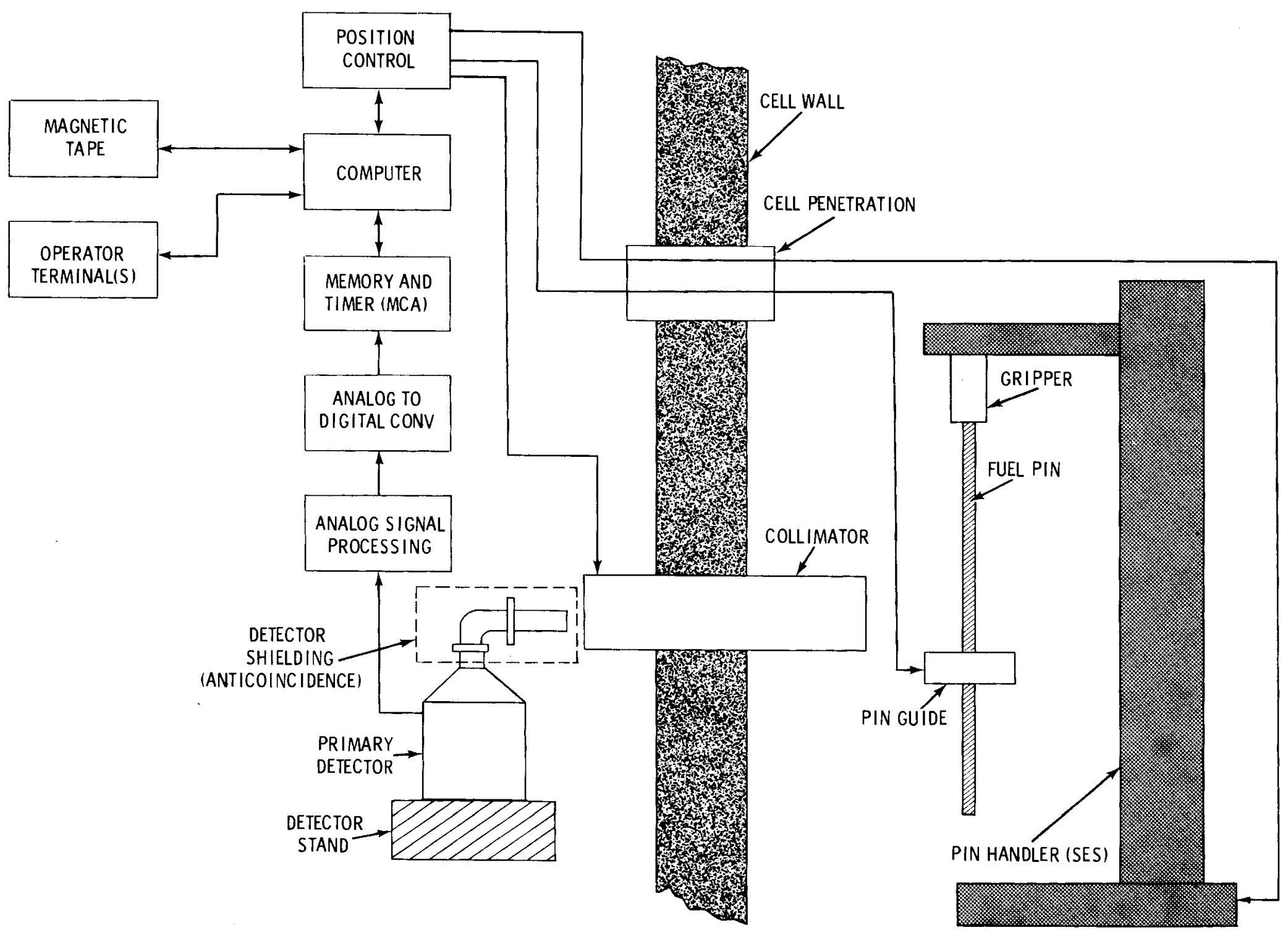

FIGURE 1. Typical Gamma Scan Facility at a Hot Cell 


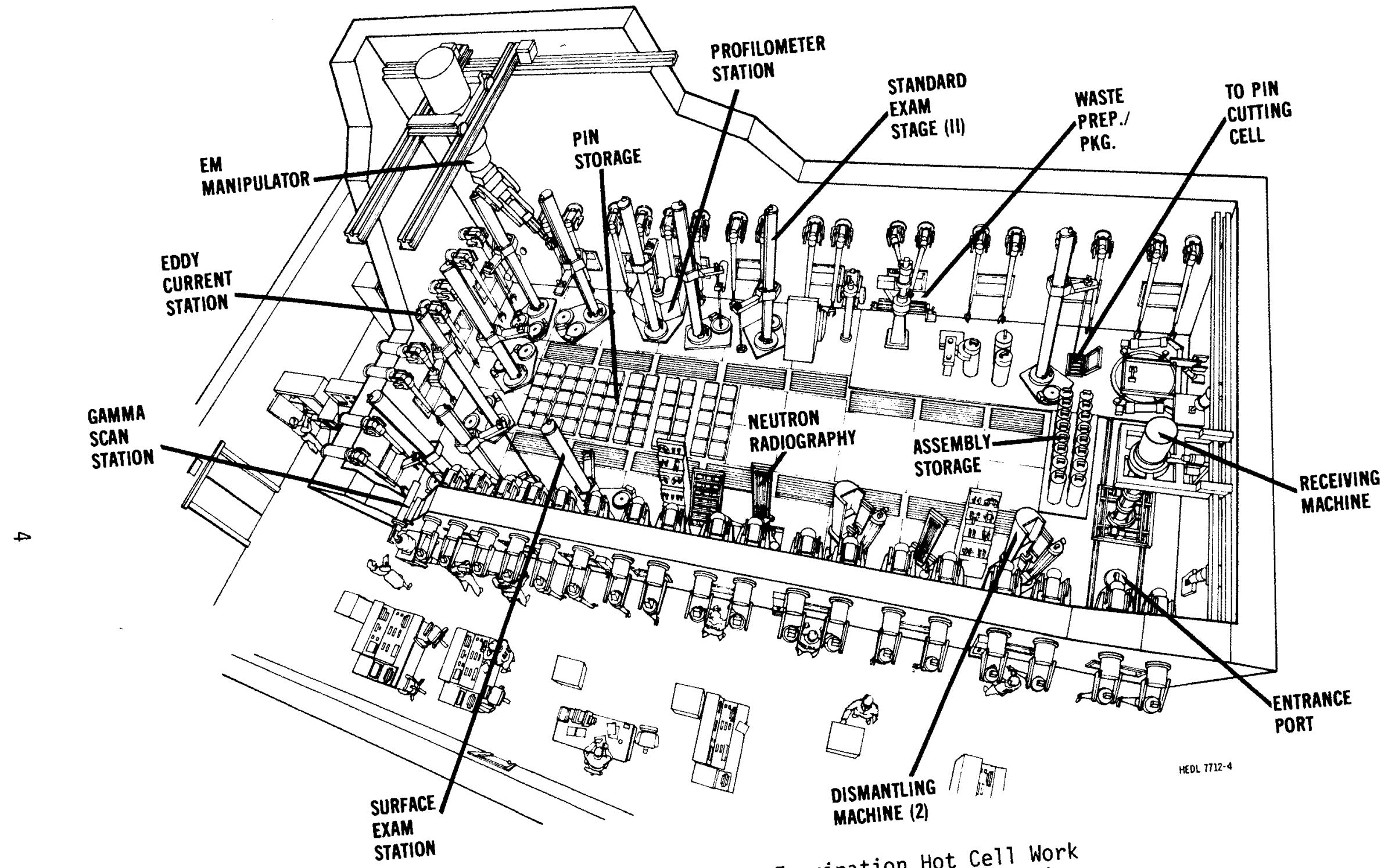

FIGURE 2. FMEF Nondestructive Examination $\left(20^{\prime} \times 100^{\prime} \times 55^{\prime}\right.$ high $)$ Station Arrangement
(22 work stations) 
into several separate stations located at the periphery of the cell at which various NDE exams are performed along with necessary mechanical manipulations. The examination equipment is designed for high throughput and low unit costs through exams using semi-automated handling and state-of-the-art testing techniques. Pin handling systems shall be highly automated and shall be able to accommodate 3000 pins of various types per year on the basis of one 8-hour shift per day, five days per week. The in-cell examination equipment shall have the following characteristics:

- remotely operable in an inert "nitrogen or argon" atmosphere at an operating pressure between 1 and 4 inches of water and at an operating temperature ranging between 70 and $100^{\circ} \mathrm{F}$.

- radiation damage resistant (average dose rate of $2 \times 10^{4} \mathrm{R}$ per hour, total exposure of $1 \times 10^{9} \mathrm{R}$ over five years) or readily replaceable

- remotely maintained, operated, and replaced using in-cell manipulators, tools and cranes and modular in design

- capable of in-place calibration traceable to the National Bureau of Standards.

Because the FMEF is a high-throughput facility:

- Components shall be selected and designed to assure maximum operating life and minimum downtime for replacement or repair.

- Maximum design simplicity shall be employed where it is consistent with the required functions and performance.

- In-cel1 equipment structural components shall be designed for a minimum service life of 10 years.

- Dynamically functioning components such as motors, bearings, gears and short life items such as seals and electronic or optical components which are used in the cell shall be designed and selected for a minimum service 1 ife of 5 years where practical. 
- When relatively frequent replacement is unavoidable, equipment shall be designed to be maintainable in place or removable using in-cell master/slave and electro-mechanical manipulators and viewing aids such as periscopes, mirrors and closed-circuit TV.

- The design goal for the mean time to cure for the ex-cell instrumentation shall be 2 hours.

In order to achieve the above design goals the station equipment shall be modular in design wherever practicable. Modules shall be:

- designed for as light a weight as practicable

- limited in physical size to fit in a cylindrical envelope 6 feet in diameter and 16 feet in length

- provided with appropriate lifting bails or lugs located to keep lifting equipment over the center of gravity of the module to stabilize it during handling

- provided with remotely operable positioning and fastening devices to assure accurate location and alignment of mating parts

- any nuts, bolts, dowel pins, or other fasteners shall be made captive and designed with appropriately tapered leads

- provided with drive units designed to allow replacement of motors without requiring removal of drive trains.

All in-cell equipment shall be designed and constructed to simplify decontamination for ex-cell maintenance or repair or shipment for storage. Surface porosity, crevices, cracks and blind holes shall be avoided in nonpainted machine surfaces and exposed metal surfaces shall have a surface finish better than 125 microinches RMS.

The FMEF process and examination equipment shall be designed to maximize nuclear, test article (fuel pin), personnel, and equipment safety. Nuclear Safety requires that accurate records be kept of the amount and location of all fissionable material in the NDE cell at a given time. This material shall be maintained in a geometric configuration that meets requirements of avoiding a critical mass. 
Test articles shall be protected from damage due to overheating or plastic deformation. Individual pins normally do not require cooling other than free circulation convective cooling, but in no case shall the surface temperature of these pins be allowed to exceed $800^{\circ} \mathrm{F}$. Plastic deformation of pins caused by dropping shall be precluded by design of administrative controls and measurement and examination techniques shall be selected which do not damage the pins.

Personnel shall be protected from radiation exposure by use of adequate shielding. Cell wall penetrations shall be designed to minimize personnel exposure and to maintain the in-cell inert atmosphere.

\section{GAMMA SCAN REQUIREMENTS}

The gamma scan equipment shall be capable of measuring the distribution of the fission products in typical irradiated fuels with a counting precision determined by the total number of counts collected from a selected fission product and spatial accuracy as determined by the SES for axial scans. Rotational accuracy will be determined by the gripper (SES) and translational accuracy for diametral scans will be limited by the accuracy of the fuel guide mechanism. The accuracy of the axial locations as provided by the SES is 0.010 inches with a rotational accuracy of $\pm 2^{\circ}$. The SES gripper will provide positioning precision (repeatability) of \pm 0.005 inch for $Z, \pm 0.015$ inch in the horizontal plane, and $\pm 0.25^{\circ}$ for $\emptyset$. In addition to the SES accuracies provided, the gamma scan collimators, detector stand and pin guide must meet the following requirements:

1) The collimator aperture must be reproducible with an accuracy of $\pm 1.5 \%$ of the aperture from 0.004 to 0.100 inches. Collimator aperture range to be 0.000 to 0.100 inches.

2) The collimator will rotate from a horizontal to vertical position $\left(0^{\circ}-90^{\circ}\right)$ with an accuracy of $\pm 1.0^{\circ}$.

3) During installation, the center of the pin guide shall be located within \pm 0.13 inch of the longitudinal axis of the collimator. 
4) The clamping guide must be capable of stepping the fuel pin past the collimator aperture with a precision (repeatability) of 0.0005 inch and an accuracy of \pm 0.002 inch.

5) The system shall be capable of handling pin diameters from 0.200 inch to 0.550 inch. The system shall be capable of scanning all but the top and bottom $5 \%$ of the fuel pin.

6) The system will be capable of taking data at increments no greater than the collimator aperture.

7) The scan positions along the fuel pin should be relatable to the data taken for other exams within +0.010 inch.

8) The $x$-axis (perpendicular to the collimator longitudinal axis) position of the primary detector must be reproducible within +0.015 inch. The $y$-axis location of the detector shall be reproducible within \pm 0.100 inch.

9) The primary detector, high purity germanium, will have as minimum characteristics a resolution of $2.0 \mathrm{keV}$ full width half maximum (FWHM) and a peak-to-compton ratio of 40:1 which can be enhanced to $300: 1$ with an anticoincidence annulus (measured at $1.33 \mathrm{MeV}$ ).

10) During axial scanning pin angulation (due to bowing) shall be limited to a conical envelope no greater than $30^{\circ}$ included angle with respect to the true vertical axis. The central axis of the pin should be maintained in coincidence with the longitudinal axis of the collimator (in the $x$-direction) within +0.030 inch.

11) As a minimum, during detailed precision scanning, two diametral scans at $90^{\circ}$ at one axial location per pin will be made. Some pins may require scans at one or two additional axial locations and/or may require scans at more than two angles. During diametral scans, axial position shall be maintained within +0.010 regardless of the pin angular position, and the central axis of the pin shall be maintained within $\pm 1^{\circ}$ of the true vertical (design goal), but in no case shall this angle be greater than $\pm 3^{\circ}$.

12) The $y$-axis location of the pin shall be reproducible within +0.100 inch. 
The general gamma scanning modes of operation and their description are listed below:

Rapid Scanning will be performed on $100 \%$ of the pins and is defined as a gross axial scan to determine the fuel column shift profile and the fuel column shift. It is desirable to separate the ${ }^{137} \mathrm{Cs},{ }^{95} \mathrm{Zr}-{ }^{95} \mathrm{Nb}$ and gross count rates. For these scans the maximum collimator aperture desirable is 0.075 inch and the scan should cover the entire fuel pin. A Detailed Gross Scan is scheduled to be performed on $30 \%$ of the available fuel pins. This is an axial scan looking at similar photopeaks to those in the rapid scan, however, the photopeaks should be Compton corrected and the collimator should be limited to approximately 0.020 inch.

Precision Detail Scans will be performed on a limited number of the fuel pins (approximately 5\%). This will consist of axial and diametral scans to examine the entire fuel column in detail. These scans should routinely detect pellet interfaces and detect accumulation of isotopes such as ${ }^{137} \mathrm{Cs}$ at the interfaces. Collimator slit openings as small as 0.004 inch are anticipated.

\section{GENERAL DESIGN DESCRIPTION}

The system consists of two groups of instrumentation, one group in the NDE cell and the other outside the cell in the operating corridor. The inthe-cell instrumentation consists of the standard SES pin handler with its associated fuel pin magazines and a special pin guide mechanism. The pin guide mechanism is bolted to, and accurately referenced to, the collimator which is mounted in the cell wall. The collimator is the beam defining mechanism and communicates between the in-cell and out-of-cell instrumentation.

The radiation detectors and electronics instrumentation are located outside the cell in the operating corridor. Immediately adjacent to the collimator are the detectors. The detectors consist of a high resolution germanium detector which is surrounded by a sodium iodide anti-coincidence detector. Between the collimator and the germanium detector is a slide 
mechanism which will expose the germanium detector to a calibrated source of radioactivity. The detectors are mounted on a detector stand which can be accurately positioned with respect to the center line of the collimator. The response of the detector will vary with the position of the beam thus requiring reproducibility of detector position within $+15 \mathrm{mils}$ in the $X$ and $Z$ directions and within $\pm 100 \mathrm{mils}$ in the $Y$ direction. This is required to maintain acceptable count reproducibility.

The signals from the two detectors go first to preamplifiers mounted near or on the detectors themselves and then into main amplifiers mounted in an instrument rack in the operating corridor. The amplifiers are selected for high count rate performance and the signal from the germanium detector is processed in a linear fashion going into an analog to digital converter where the signals are digitized and stored in a multichannel analyzer memory. The signals from the sodium-iodide detector go through an amplifier to a single channel analyzer which is used to gate the multi-channel analyzer. Data from the multi-channel analyzer which contain the count versus energy information from the fuel pin are fed into the computer system along with information from the SES positioning control microcomputer. These two sets of information are used by the computer to construct a plot of fission product intensity as a function of position on the fuel pin. The computer formats this information and outputs it to the magnetic tape unit along with the full energy spectrum collected by the analyzer. The computer also performs a control function, deciding the positions of the fuel pin and the angular position and size of the collimator for each count. The pin scan sequence is decided by the analyst and entered into the station computer from the central facility as the identified pin comes up for scanning.

The sequence of operations in scanning a fuel pin follows, assuming that the magazines are already in position:

1) The SES grapples a calibration pin (performed between scans or a minimum of once each shift) and positions it at a preselected position in front of the collimator where it is clamped by the pin guide. 
2) Preselected slit widths and counting times are used to accumulate spectrum from the calibration rod. This is stored on magnetic tape for later analysis and the pin is returned to storage.

3) The station computer then calculates the intensity of up to five isotopes (i.e., ${ }^{137} \mathrm{Cs},{ }^{95} \mathrm{Zr}-{ }^{95} \mathrm{Nb},{ }^{106} \mathrm{Ru}$, etc.) from the standard pin and sends this information to the DAPCS computer along with the standard identification. The DAPCS computer compares the photopeak intensities with a running average of the previous standard counts and prints out an alarm if the intensities vary by over three sigma from the previous counts.

4) Next the station computer requests the identification of the next pin to be scanned from the DAPCS computer and when received begins a new scan sequence. The central computer provides pin identification, area to be scanned, nominal scan rate, collimator slit width and any special scan information such as locations for diametral scans.

5) The SES grapples the selected pin in the process magazine, raises it, identifies it, and positions it near the gamma scanner, but far enough away that a bowed pin will not interfere with the collimator or pin guide (approximately 8 inches).

6) The pin is lowered until the top of the pin is 15 inches above the center line of the collimator. Then the pin is positioned so that it is directly above the center of the measurement region and the pin guide is close to restrain the pin.

7) While the new fuel pin is being taken from the process magazine, the autocalibrator positions a calibration source in front of the detector and a count of the calibration source is taken and a full spectrum is stored on magnetic tape along with the fuel pin identification tag word.

8) The station computer then calculates the intensity of selected photopeaks (i.e., ${ }^{137} \mathrm{Cs},{ }^{60} \mathrm{Co}$, etc.) and sends the intensities along with the peak positions (channel number) to the DAPCS computer. The DAPCS computer will compare these values with running averages of previous values. If the variation exceeds some nominal value (TBD) an alarm will be printed in the control room. 
9) Next the pin is positioned axially at or near the center of the fuel column, clamped and a count taken.

10) The gamma ray spectrum is analyzed for acceptable count rate data and the collimator is adjusted to obtain an acceptable count rate, if required. Video messages will be displayed for the operator if the beam scrapper must be rotated to increase or decrease the count rate. This step determines the scanning rate and can be preprogrammed for pins with similar burnup and decay. Scan increments and nominal collimator width were established in step 4 . However, the station computer will have to be programmed to balance the acceptable count rates against projected scan time. In other words scan throughput must be balanced against fuels analys is requirements.

11) The pin guide is loosened to the restrain position and the pin is lowered to the start position where the guide is again tightened.

12) The SES then raises the pin incrementally as counts are taken at positions along the fuel pin. Vertical position is referenced from the SES vertical position encoder.

13) Count data from the analyzer memory will be dumped to the station computer at each scan increment.

14) The spectral data from each increment is processed mathematically to determine selected fission product concentrations as a function of fuel pin position. This information is written onto a magnetic tape along with the full spectral information.

15) The station computer compares the peak intensities with a running average of previous intensities from the same pin and stores position, isotope and count rate information for all points which vary over five sigma from the average. These points are tagged on the magnetic tape and stored in a separate file on disc.

16) The SES continues to raise the pin as the data is collected and written onto magnetic tape until the bottom reference position is reached. 
17) If another scan sequence is to be performed on the same fuel pin, such as a diametral scan, the pin is repositioned to the selected position under SES control. During all lowering operations on the pin, the pin guide mechanism is loosened to avoid drag.

18) After repositioning for a dianetral scan, the collimator is rotated $90^{\circ}$ (vertical slit) and the slit width is adjusted.

19) The pin guide mechanism is then activated to move the fuel pin just off the collimator axis in the $-x$ direction. Next the pin is incremented in the $+x$ direction and data taken and analyzed at discrete increments in a manner similar to that outlined above.

20) The pin will then be rotated and additional diametral scans performed if one wanted either more diametral information or enough information to construct a three-dimensional activity profile.

21) Following the sequence of programmed scan operations the SES raises the pin out of the measurement region and returns it to the process magazine and the sequence begins anew.

22) Following completion of the scan, pin identification, area scanned, collimator parameters, scan rate, a midpoint spectrum and the disc file generated in item 15 are sent to the central DAPCS computer.

\section{DETAILED DESIGN DESCRIPTION}

\section{PIN HANDLING/POSITIONING SYSTEM}

The pin handling and positioning is a critical aspect of any gamma scan examinations of a fuel pin. The SES performs the pin handling positioning functions at the primary gamma scan stations. The SES is shown in Figure 3. The SES is a pedestal-mounted, remotely-operated, electrically-powered mechanical assembly designed to meet the required positioning accuracy, repeatability, velocity and acceleration limits for the fuel pin measurements. The SES is capable of positioning the pin at any selected location within its design operating envelope within the following tolerances. 


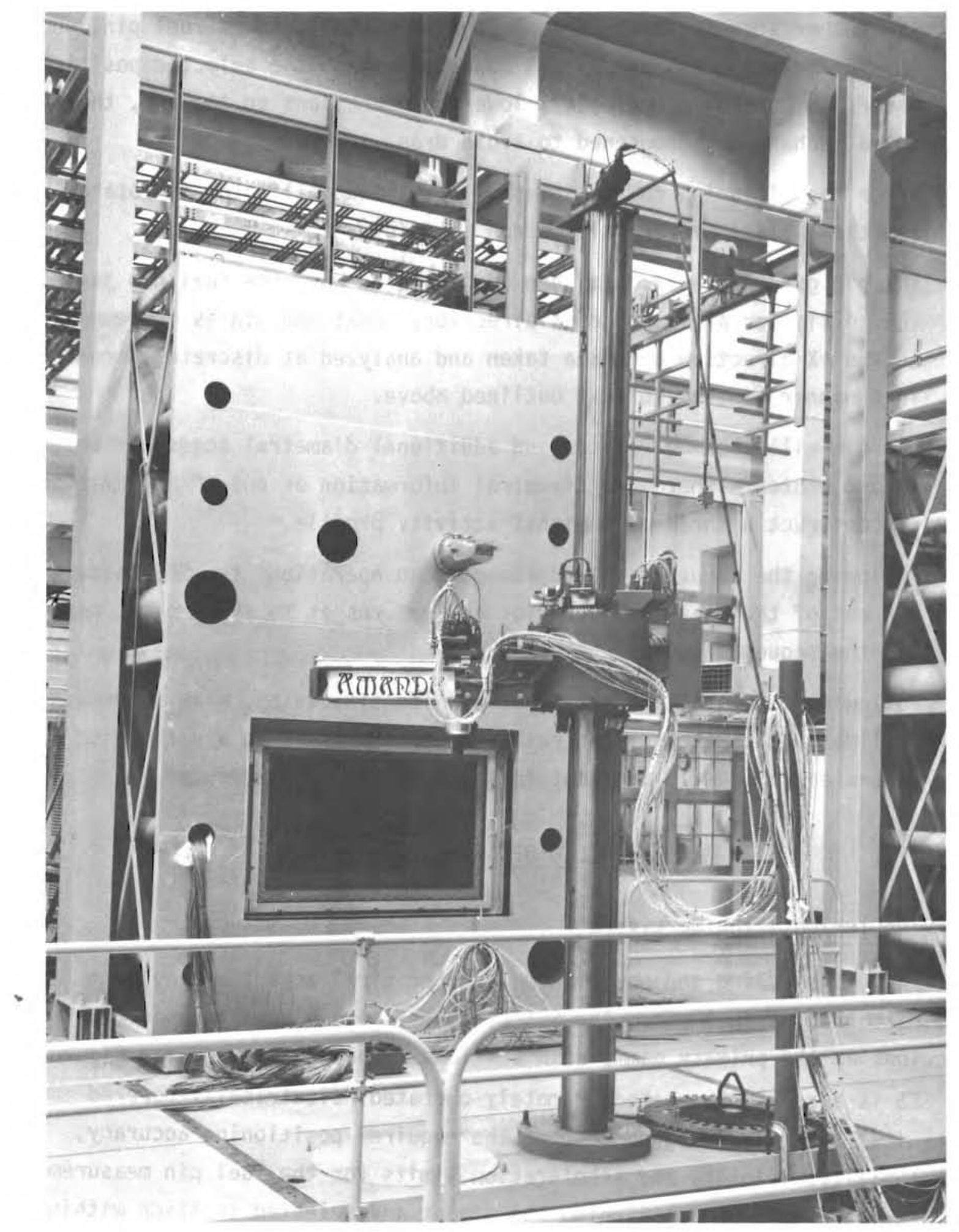

FIGURE 3. Standard Examination Stage 
- vertical position \pm 0.010 inch

- horizontal position \pm 0.030 inch.

The SES is capable of returning to a previously established position within the following tolerances:

- vertical position \pm 0.005 inch

- horizontal position \pm 0.015 inch

The SES can translate or rotate the pin at any selected constant velocity within the following ranges:

- vertical translation 1 to 120 inches per minute

- horizontal translation 0.6 to 60 inches per minute

- rotation, 0.05 to 5.00 revolutions per minute.

SES acceleration is limited to $0.1 G$ maximum to minimize pin swinging and vibration. A Complete description of the SES and its associated gripper mechanisms can be found in supporting documentation.

\section{PIN GUIDE MECHANISM}

Prel iminary conceptual drawings of the recommended arrangement for a pin guide mechanism are shown in the appendix. The mechanism consists of a $\mathrm{V}$ block arrangement spanning the collimator active region and four remotely activated fingers which capture and hold the pin in the $V$ block. The unit is mounted on the in-cell side of the collimator housing to maintain alignment accuracy and will be remotely detachable from the collimator for servicing.

A dc motor with integral gearhead and a torque limiting clutch control the capture fingers. Motor current is also monitored to prevent overdriving which may damage the fuel pin. A second motor (stepping motor) translates the $V$-block and capture finger assembly with respect to the collimator. This assembly is driven by a ball screw and has ball bushings riding on hardened ways. The position is read out by an encoder (not shown). This permits accurate positioning in the $X$ direction for diametral scanning. All surfaces which contact the fuel pin ( $V$-block, fingers) will be rounded to minimize contact area and will have a hard chrome plating. 
The pin guide mechanism is designed to capture pins within a 5-inch radius circle (maximum design bow $=5$ inches). Once the pins are captured, the $X$ drive mechanism can drive the pins over a 2 -inch range $( \pm 1$ inch) with an accuracy of \pm 0.002 inch and a resolution of 0.0005 inch. The mechanism will be designed to permit scanning ( 2 direction) within $5 \%$ of either end of the fuel pin.

To prevent excessive distortion of bowed pins, it is recommended that the $V$-block assembly be gimballed to permit up to $\pm 15^{\circ}$ angular movement relative to the Z-axis. The center of rotation of the V-block should be at or very close to the intersection of the collimator-axis and Z-axis to avoid appreciable pin-to-collimator relative movement as the pin is traversed axially. During diametral scanning the pin guide will be locked in position with the pin axis located and maintained within $\pm 1^{\circ}$ of (design goal), but not greater than $\pm 3^{\circ}$ from true vertical (see page 6 , Item 11 ).

\section{COLLIMATOR}

The collimator for the gamma scan system is a precision mechanism with automatically variable slits and automatic rotation through $90^{\circ}$. The collimator slit can be rotated from $0^{\circ}$ (horizontal) to $90^{\circ}$ with an accuracy of $1^{\circ}$. The collimator will have 0.6 -inch wide slits variable from 0.000 to 0.100 inch. The central axis of the collimator will be aligned with the central axis of the pin guide mechanism within an overall accuracy of \pm 0.130 inch.

The collimator will consist of an outer fixed shell (see appendix) which will extend through the shielding wall into the cell. This portion also acts as the support for the pin guide. This outer portion (part 1) will have an outside diameter of approximately 12 inches and will have an end plate (interior end) made of aluminum with the thickness reduced to 0.050 inch in the region of the collimator slits. This outer shell will be sealed to the penetration flange of the NDE cell and will maintain an airtight seal. A second portion of the collimator (part 2) will slip into this outer portion (part 1) and will bolt to the flange of part 1 and will not rotate. Contained within the second portion (part 2) will be the rotating inner cylinder of 
the collimator (part 3 ) which will rotate in bearings at both ends. The slits are integral to this third part. It must be possible to withdraw the inner portions of the collimator from the outer sleeve and replace them without exceeding the limitations on accuracy between the pin guide mechanism and the collimator. Collimator slit width will be controlled by a stepping motor. Built into the jaws will be LVDT transducers used to measure the true slit width. The two tungsten pieces forming the front portion of the collimator must be parallel within 0.0005 inch and the angular deviation of these two tungsten blocks must be less than 0.05 degrees from the true center of the collimator. Built into the rear of the collimator on the operating corridor side, will be four beam scraper apertures. The four apertures will be in a separate piece of tungsten which can be rotated to select one of the four apertures. Aperture position and collimator rotation will be hand-operated with switches to monitor operation.

Other than the straight through opening for the primary beam there will be no direct paths through the collimator. The appendix shows the assembly drawing of the collimator and gives some of the design considerations.

Not shown on the drawing are switches that will be installed to indicate the position of the rotating portions of the collimator. LED optical switches will be used to indicate the position of notches on a disk or reflective tape attached to the collimator and to the aperture cylinder. These will be used to indicate the position of the collimator $\left(0^{\circ}\right.$ or $\left.90^{\circ}\right)$ and the position of the aperture cylinder $\left(0^{\circ}, 90^{\circ}, 180^{\circ}, 270^{\circ}\right)$. The switches will provide information on collimator parameters to the station computer. Accurate positioning wi11 depend on the mechanical detents.

The collimator configuration in conjunction with the detector cart must meet the $1 \mathrm{mrem} / \mathrm{hr}$ dose rate 1 imitation of HEDL TC-846. The geometry is complex and calculations were not attempted since measurements can be made at the $324 \mathrm{Bldg}$. on the prototype collimator. Measurements will show if access to the area between the collimator and detector stand must be 1 imited when a rod is in position. 


\section{DETECTORS}

The primary detector for the gamma scanning system will consist of an intrinsic germanium detector with an overall efficiency of $15 \%$. The detector will be selected to have a resolution at FWHM of less than $2.0 \mathrm{keV}$ at $1.33 \mathrm{MeV}$ and a width at 10th maximum which is less than 2 times the FWHM. The peak to Compton ratio for the detector will be greater than 40:1 and the detector will be mounted in a horizontal dipstick configuration. The preamplifier will be an integral part of the detector system. The end-cap of the germanium detector will reach into or beyond the center of a sodium-iodide anticoincidence annulus which will be 10 inches in diameter by 8 inches long. The detector will be off the central axis of the anticoincidence detector (see the appendix). With the anticoincidence annulus in operation, the detector system will provide a peak to Compton ratio of greater than 300:1. The electronics for the sodium-iodide anticoincidence annulus will use delay line clipping to permit maximum count rates for anticoincidence operation.

The detectors will be mounted in a detector stand opposite the collimator (part $C$ of the appendix). The detector stand will be adjustable so that the axis of the primary detector can be located or reproduced within $\pm 15 \mathrm{mils}$ with respect to the center line of the collimator. Reproducibility for the distance from the wall of the cell must be within \pm 100 mils. The detector stand will also provide shielding for the detectors and for personnel in the corridor. The detectors must be surrounded by a minimum of 4 inches of lead shielding. Switches on the two carts will provide an indication that they are in the correct position. If the carts are not in position, this will indicate a potential for radiation exposure from a collimated beam. This condition should be alarmed in the central control room.

\section{GAMMA SCANNER ANALOG ELECTRONICS}

The counting electronics will consist of state-of-the-art amplifiers and analog to digital converters, etc., meeting the Nuclear Instrument Modules (NIM) standards as outlined in AEC report TID20893. A block diagram of the electronics is shown in Figure 4 while Table 1 identifies typical components. 


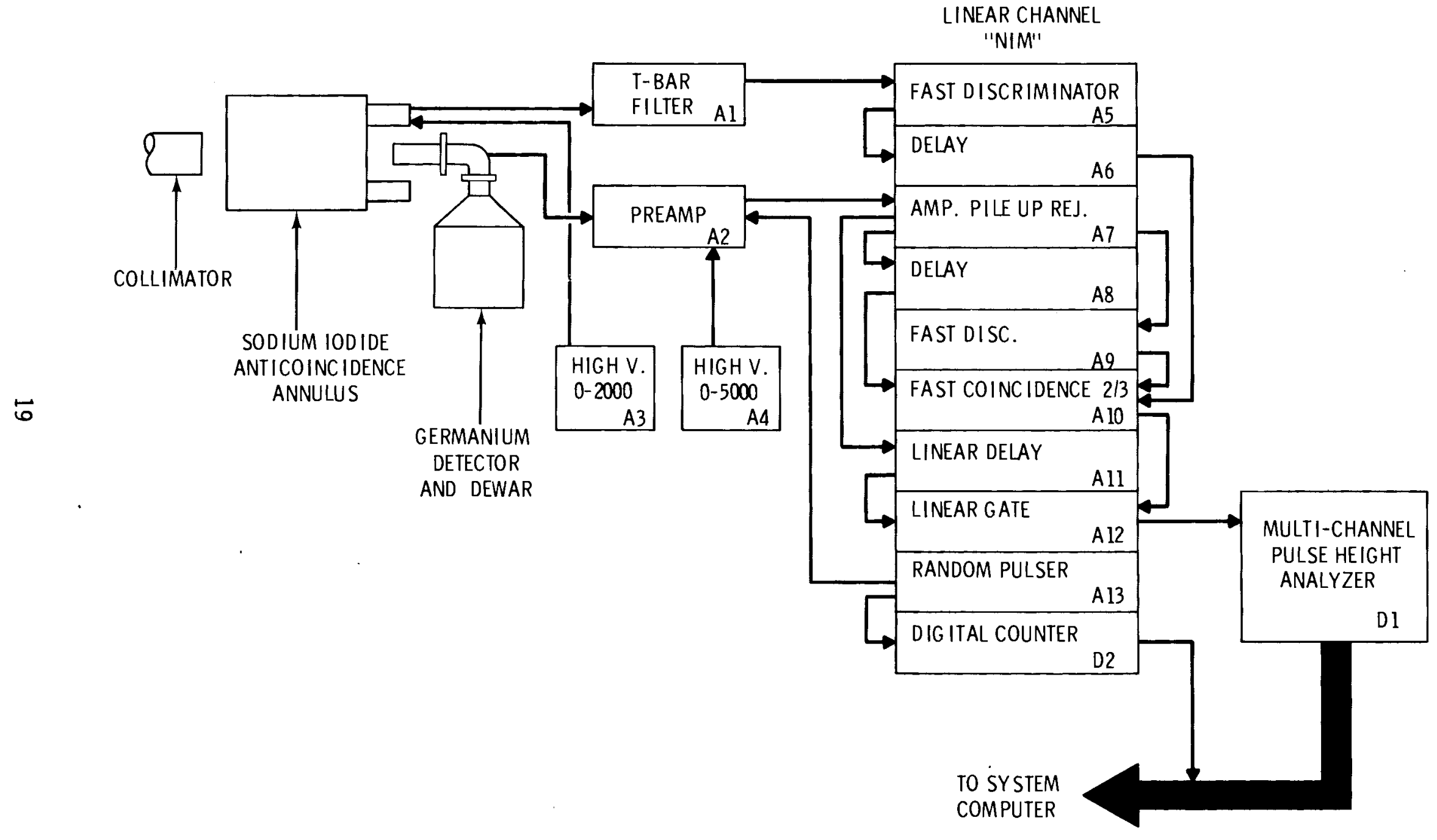

FIGURE 4. System Counting Electronics 
Basically, the electronics as specified in Figure 4 consist of a high quality amplifier with pileup rejector for the primary detector and a fast coincidence system to block analysis of signals distorted by pulse pileup or signals coincident with an event in the antocoincidence annulus. It is recommended that a clipping network ( $\mathrm{Al}$ ) be included to shorten pulses from the anticoincidence detector and thus reduce dead time from this source. The system also includes a random pulser to test the system for dead time losses. Comparison of an independent count from the pulser with the counts in the analyzed pulser peak will provide a measure of system dead time losses. Pulser peak location will also indicate long-term drift problems. All hardware should be equivalent to or better than items specified in Table 1.

Alternative electronic configurations are feasible. For instance, rather than using a coincidence module, a time to pulse height converter with integral single channel analyzer could be employed. This would provide an anticoincidence gate pulse for $\mathrm{NaI}$ annulus/germanium detector coincidences, but for high count rates this would have to be logically summed with inhibit pulses from the pileup rejector to include this gating function.

GAMMA SCANNER DIGITAL ELECTRONICS

The gamma scanner digital electronics consist of the multi-channel analyzer and a counter as shown in Table 2. The multi-channel analyzer will interface via a high-speed serial link to the station computer. Since the control system electronics will be CAMAC based, a CAMAC based analyzer system could be employed. However, a stand-alone MCA has independent display capabilities which will simplify system setup. The more sophisticated MCA systems provide independent spectral analysis which will also aid in system setup and operation analysis. The new high-speed interfaces ( 56 kbaud) or memory "ping ponging" will overcome the present limitation of stand-alone MCA systems. To maintain high throughput, the multi-channel analyzer must be specified properly. The unit must collect data in one portion of the memory while transferring data from the other portion unless the high-speed interface is available. Sample specifications are available. 


\section{TABLE 1. Gamma Scanner Analog Electronics}

$\frac{\text { Name }}{\text { T-Bar Filter }}$
Preampl ifier
High Voltage Supply
High Voltage Supply

Functional Description I. D.

Pole-Zero Network to shorten (clip) pulses from $\mathrm{NaI}(\mathrm{T} R)$

nnulus.

\section{Selected Specifications}

Specially built network to shorten current pulse duration in $\mathrm{NaI}(\mathrm{T} \ell)$ detectors and thus reduce pile-up effects.

Amplification and impedance detching for signal from Ge detector

A2 To be included with detector.

Bias supply for photomultiplier Bias supply for Ge detector

Energy threshold for anticoincidence annulus.

Delay

Ampl ifier with

Pile-Up Rejector

Module to delay signal from A5

A3) Rack-mounted, non-NIM.

$100 \mathrm{MHz}$ leading edge disc, with delayed reset $\leq 0.05 \mathrm{mV} /{ }^{\circ} \mathrm{C}$.

A6, A8 Delays or gate and delay generators are required. A7 for coincidence.

Fast Discriminator

provides and provides pulse pile-up information. At high count rates pulse pile up will distort the energy pectrum.

Amplifier to incorporate baseline restorer with automatic threshold. Peak shift with count rate to be $<0.025 \%$ up to $100 \mathrm{~K}$ counts $/ \mathrm{sec}$. Peak broad-
ening to be $<20 \%$ at same count rate. $<0.0075 \% /{ }^{\circ} \mathrm{C}$ -

Energy threshold for Ge detector signals using constant fraction discrimination for energy independence.

This item to include a timing amplifier if required. Walk $<+2 \mathrm{nsec}$ from 0.1 to $5 \mathrm{~V},<0.5 \mathrm{mV} /{ }^{\circ} \mathrm{C}$.

Fast Coincidence

Logic signal is provided if accepted Ge detector and anticoincidence annulus or pulse pile-up signals are present. This logic signal is used to block analysis of Ge detector signals.

Linear Delay

Provides delay of Ge detector signal (gamma ray) to match with

Linear Gate Provides gating of linear signal dence logic signal.

Random Puiser

Provides random pulse which is used to measure count losses in the counting system.

Variable resolving time up to $0.1 \mathrm{usec}$ with both coincidence and anticoincidence inputs.

$\leq \pm 0.05 \% /{ }^{\circ} \mathrm{C}, \leq+0.05 \%$ nonl inearity above $0.1 \mathrm{~V}$

Provides operating power and mounting space for equipment

Variable gate duration, normal \& pulse inhibit modes, $\leq 0.015 \% /{ }^{\circ} \mathrm{C}, \leq 0.15 \%$ nonl inearity, $\leq 0.25 \%$ count rate shift at $65 \mathrm{~K}$ counts $/ \mathrm{sec}$.

Variable rise, fall and amplitude with pulse rates (random) from 10 to $1 \mathrm{MHz},<+0.02 \% /{ }^{\circ} \mathrm{C}$ $\leq \pm 0.05 \%$ amplitude shift with rate. 
Table 2. Gamma Scanner Digital Signal Processing Equipment

Name

Multi-Channel Analyzer $A D C$

Digital Storage

Counter
I.D.

Code

Selected Specifications

Converts linear (analog) signal from $\mathrm{Ge}$ detector into digital signal for storage.

Interim storage for digital signals from ADC. Memory stores the number of times an event with, a selected magnitude occurs.

Digital counter which counts the absolute number of pulses from the pulser. Comparison of these counts with pulser counts in spectrum yields information on losses due to count rate.
D1

Digitizing rate $=100 \mathrm{MHz}$, Integral nonl inearity $<+0.05 \%$ and differential < $+1 \%$ over top 99\%. Baseline and gain drift $<0.01 \% /{ }^{\circ} \mathrm{C}$.

Two blocks of 4096 channels, $2^{20}$ -1 counts per channel. Memory ping pong capability with simultaneous readout and acquisition in separate memory groups.

Scalars with a minimum of $25 \mathrm{MHz}$ counting rate and positive gate input (CAMAC). 
In a typical operational sequence, when the MCA has completed a count and informed the station computer, the computer will increment the handler to the next position. As soon as the handler is in position, the station computer will start data collection in the second 4096 channels of memory and begin transfer of the data from the first 4096 channels into its memory for analysis and formatting for writing on the magnetic tape. At a typical 9600 baud transfer rate, data transfer will take approximately 70 seconds. Higher data transfer rates are possible in most cases, but will depend on computer type and transmission line length. Newer interfaces are in development with data transfer rates up to $56 \mathrm{kbaud}$. This would eliminate the need for ping ponging of memory since data transfer (binary) would be less than 10 seconds.

\section{CONTROL SYSTEM ELECTRONICS AND COMPUTER}

Figure 5 shows the control system electronics for the hardware unique to the gamma scanner while Table 3 identifies typical items. The hardware is based on CAMAC electronics (TID25875). The various digital signal sources were discussed in the previous sections.

Computer requirements are difficult to define, but based on the spectral analys is requirements a minimum system will have $48 \mathrm{~K}$ bytes of memory with a $256 \mathrm{~K}$ byte floppy disk for program and data storage. Features such as battery backup for the MOS memory and automatic power fail and restart protection are mandatory. In addition, a floating point processor and a hard disk would be very helpful for data processing and program development. The unit must also have both a hardcopy and video operator terminals and an RS-232 interface available for the MCA.

A high quality magnetic tape unit must be available for data storage. If a full spectrum is taken every 0.05 inch over approximately 40 inches (axial scan) this will entail 800 spectra for a single pin. Approximately 500 spectra (4K channels) can be stored on a 10-1/2-inch reel operating on a 9-track, 800-bpi tape drive. Position information and summary data will also be stored on the tape with each spectrum. It is clear that a 40 -inch 


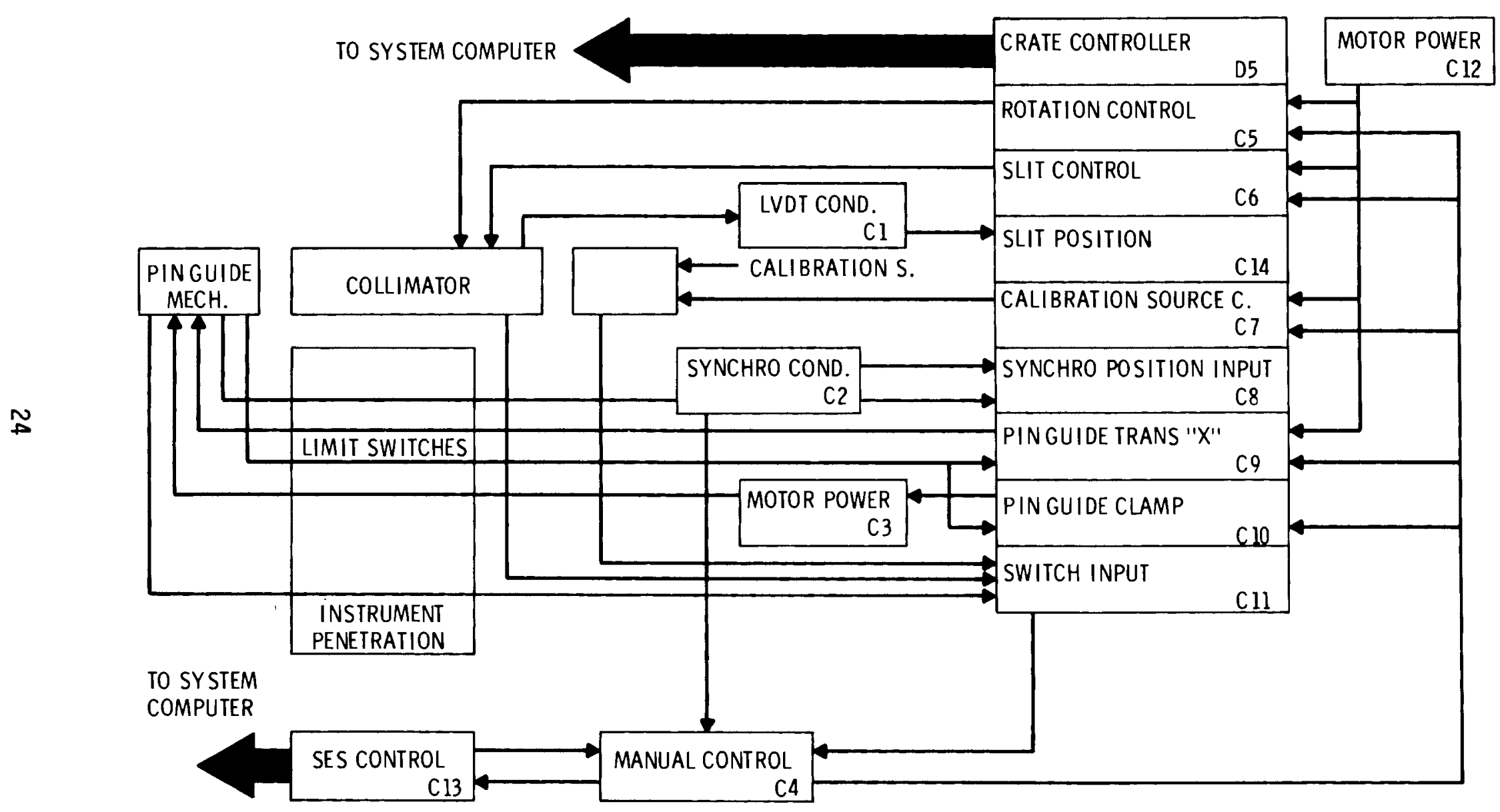

FIGURE 5. System Control Electronics 


\section{TABLE 3. Gamma Scanner Control System Items}

Name

LVDT Conditioner

Motor Power

Motor Power

Manual Control

Si it Control

Pin Guide Translation
Synchro Conditioner

Switch Input

CAMAC Crate

CAMAC Controller

Digital Counter
Functional Description

Interfaces and converts LVDT signals to a fixed range digital display with digital output.

Power supply and current limit for dc motor on clamp.

Power supply for dc servo motors.

Manual control for servo motors.

Adjusts collimator slit width.

Translates pins in $x$ direction.

Digital input module.

Converts position synchro information into $\mathrm{BCD}$ digital signals.

Interface for switches used to monitor collimator rotation and pin clamp position.

Power for CAMAC modules.

Interface to computer dataway.

Counts pulses from random pulser for deadtime correction.

I.D.

Code

Selected Specifications

Cl LVDT signal conditioning unit operating at $110 \mathrm{~V}$ and providing $\pm 10 \mathrm{~V}$ output for $50 \mathrm{mV}$ input (2 each). Must have zero offset, gain controls and BCD output.

Motor specifications to be determined. Similar to Bodine 938 control.

Fabricated item which interfaces with motor controllers ( $\mathrm{C} 6, \mathrm{C} 3, \mathrm{C} 10)$ and permits central operator control and status indication (C9). (Must also include digital readout for $\mathrm{Cl}$.)

C6 DC servo motor controller and interface to CAMAC dataway for computer control. Must also interface with $\mathrm{C5}$ and must have selectable operating speeds.

C7 CAMAC digital input module for readout of LVDT.

C9 Dual speed synchro and conditioner which will readout synchro and also interface to dataway. Must also have a display for incorporation into manual control $\mathrm{C} 5$.

C12 Fabricated item which displays status of switches used to indicate detector stand is in position, angle of collimator, pin clamp limit switch activation, emergency stop, and a minimum of two extra switch readouts. Must have manual and CAMAC readout and capability of dataway activation of E-stop. E-stop and limit switches must halt motors controlied by $\mathrm{C} 6$ and $\mathrm{C} 10$. Can be part of $\mathrm{C} 5$.

Type A-1 controller to interface with computer.

Must be capable of readout on CAMAC dataway. 
scan will require two 10-1/2-inch reels unless data compression techniques are employed. This should be considered during software development. The following guidelines will assist in limiting data storage.

1) Store only selected peak intensities, gross counts and position information for gross axial scans (48 tapes).

2) When storing full spectra eliminate all low-energy channels (0-400 keV).

3) Reduce all detailed gross scan tapes to a summary tape either off-line or during scanning by buffering on the disk. The tape would consist of tagword, position information, selected peak intensities and the full spectrum at every 25th position. A running average of peak intensities will be maintained and when the intensity of an isotope varies by more than a selected amount (TBD) the full spectra from five positions each side of this point will be saved for later analysis (230 tapes).

4) Spectra from all detail scans will be saved (900 tapes).

\section{SOFTWARE}

The various vendors of multi-channel pulse height analyzers have developed their own software tailored to the applications of the gamma-ray spectroscopist. Table 4 shows the vendors, the languages used and the names of the applications software where applicable. The major vendors are currently developing improved versions of their software written in Fortran IV. Fortran IV packages operating under RSX-11M were delivered in mid-1979. In most cases the languages are interpretive and operate in an interactive mode. The software is very powerful for the typical spectroscopist, permitting various operations such as: 1) energy calibration, 2) efficiency calibration, 3) statistical reporting, 4) automatic peak identification, 5) decay correction, 6) peak searching, 7) peak intensity with background correction, 8) analysis from mass storage, 9) report generation, 10) multiplet identification, 11) etc.

Many of the analytical features of the software are needed for the gamma scanner, but the interactive features are not required since the software will be tailored to the application. To accomplish the gamma scan requirements 
TABLE 4. Languages and Operating Systems From Various Multi-Channel Analyzer Vendors

\begin{tabular}{|c|c|c|c|}
\hline Vendor $(a)$ & Operating System & Language & Applications Software \\
\hline ORTEC & $\mathrm{RT}-11, \mathrm{RSX}-11 \mathrm{M}^{(\mathrm{b})}$ & ORACL & GELIGAM \\
\hline CANBERRA & RT-11, RSX-11M & CLASS & SPECTRAN III \\
\hline NUCLEAR DATA & RSX-11D/MIDAS ${ }^{(b)}$ & FORTRAN/As sembly & $\begin{array}{l}\text { Basic Physics, Nuclide } \\
\text { Identification, Power Plant }\end{array}$ \\
\hline TRACOR NORTHERN & RT-11 & FLEXAN & --- \\
\hline
\end{tabular}

(a) Languages and applications software are trademarked by the various vendors.

(b) Trademarks registered by Digital Equipment Corporation. 
the software for the station computer must be able to accomplish the following analytical functions: peak centroid location, peak intensity calculation with background correction, and peak width. Along with these simple analytical functions plus station monitoring and control, the computer will be busy. The software will provide a summary analys is of data and detailed analysis will be done from the recorded magnetic tapes.

The commercially available software packages will not run on other than Digital Equipment Corporation computers of the 11 series. Modification of the programs would be difficult. Specialized analytical packages have been developed at several of the DOE laboratories and run on other systems. Following selection of the station computers acquisition of an appropriate software package and tailoring of this software to operate with the gamma scan hardware is recommended.

Software reduction will limit the speed at which the gamma scanner can operate. As mentioned previously, it will take approximately one minute to transfer the data into the computer at 9600 baud. Data reduction of up to 10 photopeaks will take less than 1.5 minutes. Adding the 2.5 minutes from above to an additional minute allowed for pin repositioning, handshaking and writing on tape indicates approximately 3.5 minutes between the start of one axial count and the start of the next. This number is a maximum and reduction to two minutes should be feasible. In most precision scans the count time will be several times this value.

Table 5 lists some of the types of data that will be handled by the station computer.

Future MCAs will allow peak intensity computations in the MCA with readout to the computer. The computation time is less than one second, but is not as accurate as a computer analysis. By proper implementation of the software the same calculation time should be possible in the computer. The delays will then be in data transfers. Baud rates several times the 9600 rate are possible. Several developments are currently in progress which should improve data transfer rates such as the new RS-422 buss and interfaces 
TABLE 5. Types of Data

Name

Operator Data

Counting Data

Position Data

Calibration Data

Summary Data

Output Data

Operator Output Data

Inventory Data

Storage Media Data
Description

Information entered by the operator (pins to be scanned, scan lengths, scan procedures, photographs to analyze, etc.).

Raw data from radiation sensors of count rate versus photon energy.

Data showing the position of the SES when counting data is acquired as well as the position and size of the collimator.

Data obtained by counting a standard if desired.

A record of integrated peak areas and position data for a fuel pin.

A record of summary data and counting data written sequentially on magnetic tape for further analysis.

Data output on a video terminal consisting of test numbers, procedures, a plot of summary data, etc.

Identifications for fuel pins in magazine(s) at Gamma Scanning Stations will be obtained from the DAPCS. These identifications will provide a cross check when each pin is handled.

Identifications of tapes mounted on and dismounted from the Gamma Scanning Stations will be sent to the DAPCS for data storage accounting. 
capable of data transfer at 56 kbaud. During final MCA selection, emphasis should be placed on maximum data transfer rates with the selected station computer.

\section{SYSTEM CALIBRATION}

System calibration is performed for three major functions: energy calibration, efficiency calibration and to test reproducibility of the counting.

For energy calibration of the system, a simple positioner (calibrator) will be located between the exterior side of the collimator and the detectors. The positioner will consist of a rotating disk with all but the sector near the collimator in a shielded housing. The disk will have one location with an open hole to pass the primary beam and several other locations with a depression to hold a source. The primary calibration source will consist of a mixture of ${ }^{137} \mathrm{Cs}$ and ${ }^{60} \mathrm{Co}$. This source will be traceable to the National Bureau of Standards. This source will be used to obtain the system energy calibration and will permit one to derive information on the stability of the detector system.

It is not certain that an absolute calibration (efficiency calibration) will be performed for the gamma scan system. If such a calibration is performed there are two methods that can be used. The first technique, which will also give the least error, is to simply count a typical fuel pin under routine control of the scanning system. Later this same pin is tagged for destructive analysis and radiochemical analyses are made of the fuel to determine the absolute amount of various nuclides present at the counted positions. This analysis along with the previous counting results is used to perform an absolute system calibration. The second technique is to calculate the system efficiency by carefully accounting for all variables in the counting.

The third type of calibration is used to check reproducibility of counting. The calibrator will not give information on SES or collimator reproducibility, but simple counting of a "standard" fuel pin can provide this information. A random pin should be tagged as a standard and counted repeatedly over a one-month period at which time another pin is selected as 
TABLE 6. Rapid Scanning Electronics

\section{Name}

Single-Channel

Analyzer

Gate \& Delay

Scalar

$\omega$

Timer

Communication

Interface

Bin \& Power

Supply

\section{Functional Description}

Selects a discrete energy interval

from the detector pulses

Delays the pile up inhibit signal

from the amplifier for proper

gating of the timers and scalars

Counts pulses from selected energy regions

Times count sequence

Takes counts from the scalars, formats them and transmits them to the station computer.

Houses counting modules and provides power
I.D.

Code

$\mathrm{S1}, \mathrm{S} 2$,

S3

S4

S5, S6,

$\mathrm{S7}, \mathrm{S} 8$

S9

$\$ 10$

\section{Selected Specifications}

$<0.005 \% /{ }^{\circ} \mathrm{C}$, LLD, SCA and ULD outputs, pulse pair resolution $<0.65 \mu \mathrm{sec}, \mathrm{dc}$ input with trimpot discriminator.

Delay up to $100 \mu \mathrm{sec}$ with variable delay, amplitude, and width. Delay jitter $\leq 0.02 \%$ of range.

Scalars with a minimum of $25 \mathrm{MHz}$ counting rate and positive gate input (CAMAC or NIM).

Timer with gate input and timer range from $0.1 \mathrm{sec}$ to $800 \mathrm{sec}$ (CAMAC or NIM).

Either CAMAC controller or RS-232C compatible 9600 baud interface.

Power for modules. 
a standard. This pin must be counted a minimum of once per shift. The counts can be quite brief since counts at two or three locations with predetermined parameters ( $X, Y, Z, \emptyset$, collimator $\theta$ and slit) will be sufficient to check reproducibility.

\section{RAPID GAMMA SCANNING}

Gamma scan throughput is seriously limited by the data collection times. Although a sodium-iodide detector will double the available count rates, its poor resolution is not compatible with the data collection requirements, therefore the sodium-iodide detector was eliminated from further consideration as a primary detector.

For rapid axial scans it will be necessary to bypass both the anticoincidence detector and the multi-channel analyzer to reduce dead time in the counting system. Figure 6 and Table 6 show the electronics required for rapid collection of gross counts, pulser counts and two photopeaks. The right hand block can be configured in either NIM or CAMAC modules. The use of CAMAC is recommended with replacement of the communication interface by the crate controller. The data will not include corrections for Compton background, but this could be approximated by addition of single channel analyzers and scalers counting Compton regions near the photopeaks. It is recommended that the scanner be run continuously during these scans at TBD inches per minute. Since it will take $43 \mathrm{msec}$ to read out the scalers on a 9600 baud RS-232 1 ink to the computer, with a 5-second count time the readout will take less than $1 \%$ of the count time. During the readout time the pin will travel less than 0.001 inch at a scan rate of 1.2 inch/minute.

\section{SYSTEM RELIABILITY}

It is difficult to estimate failure rates for such a system. Inquiries to several manufacturers failed to produce any MTBF data. Based on experience, a system failure will occur once every four months. Most of these are likely to be peripheral failures associated with the computer hardware (i.e., disks, tape deck, etc.). 


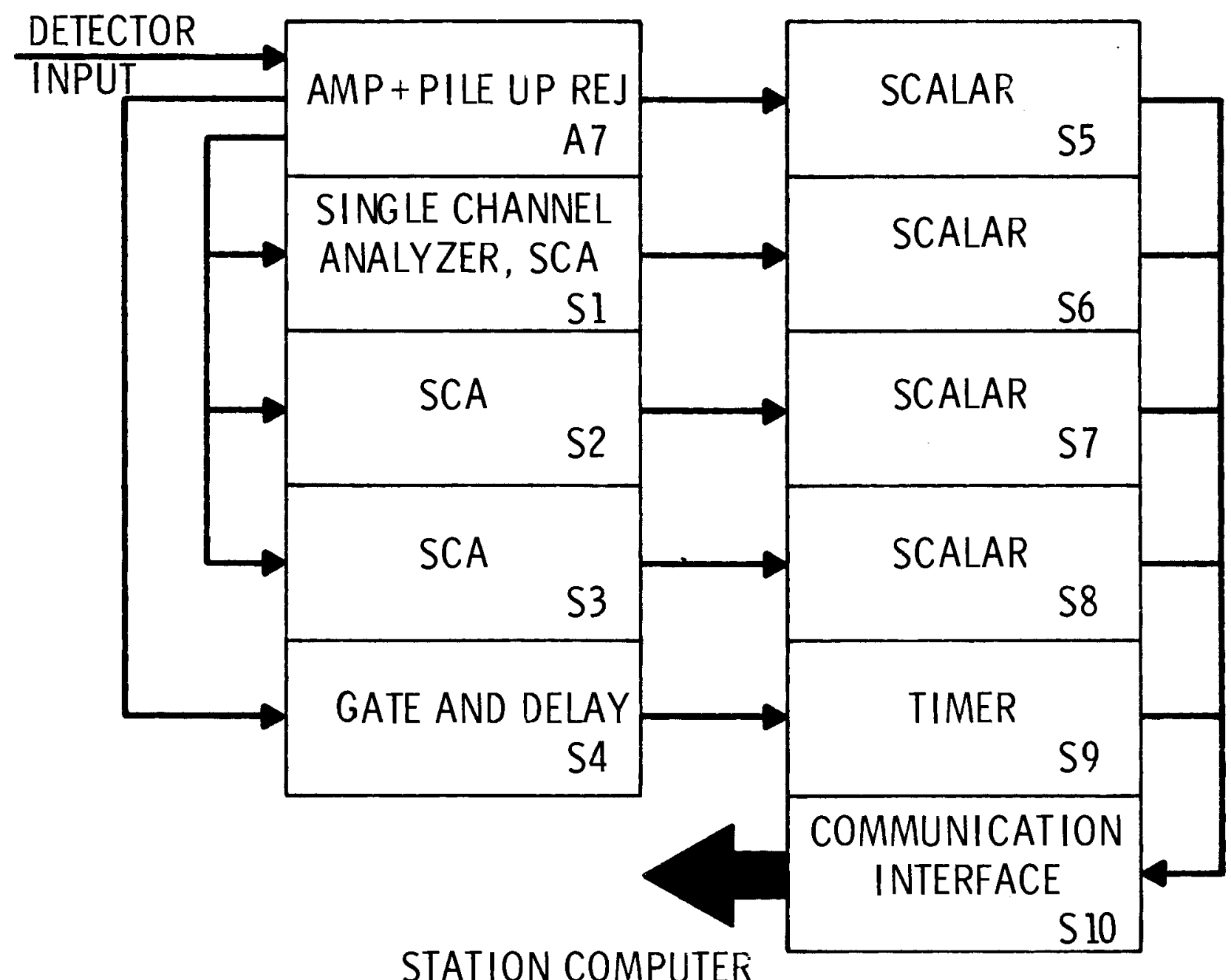

FIGURE 6. High Count Rate Electronics. (The right hand column of electronics can be either NIM or CAMAC.) 
Most of the counting electronics are modular and a spare is recommended for each type of module since repair of a module is likely to take over 8 hours. Spares cannot be justified for the detectors and repair of the multi-channel analyzer can best be handled by a field engineer from the company. If repeated failures occur, spares can be stocked since field service is likely to take 48 hours. If more than one system is purchased, spare parts should be purchased as recommended by the vendor.

The collimator and source holder are electro-mechanical devices which should not fail over an operating period of five years. More failure data will become available on the collimator during the tests in the 324 Bldg. Failure of the source holder is not critical to system operation.

In general, gamma station hardware reliability should exceed that of the SES and station computer peripherals.

\section{DEDICATED AXIAL SCANNER}

Early in this study it became clear that it would be difficult to meet the gamma scan throughput requirements with the available stations. The most favorable alternative concept to provide additional throughput is the dedicated axial scanner. The concept is illustrated in Figure 7 . The SES places a fuel pin in an adapter plate on the pin clamp mechanism, releases it and swings out of the way. The $Z$ drive of the dedicated scanner lowers its gripper which grips the pin and starts an axial scan sequence. Upon completion of the scan the pin is lowered and released for the SES to retrieve and replace in the magazine. The collimator does not have rotational capability in this configuration. Several of these systems can be serviced by a single SES. 

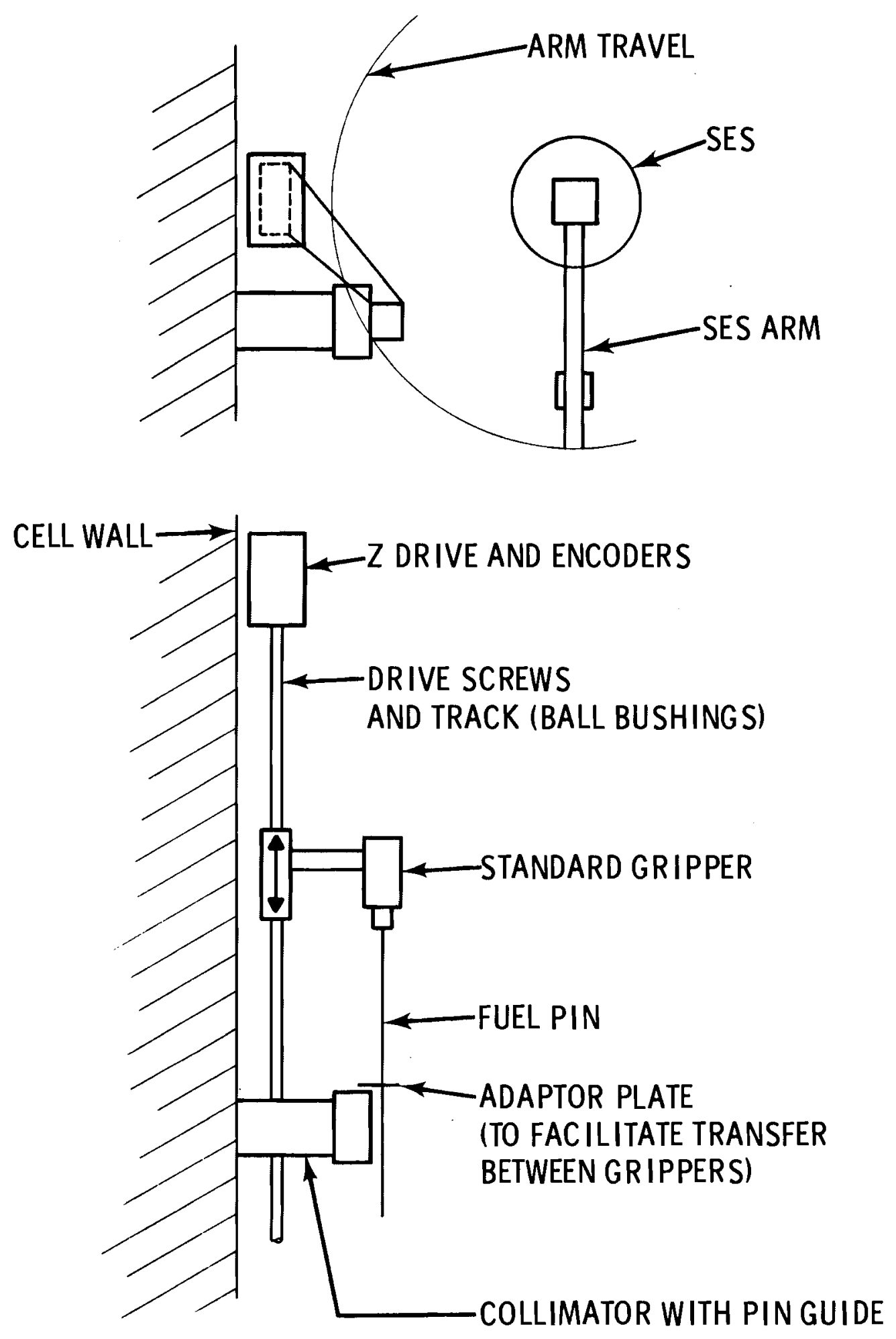

FIGURE 7. Dedicated Axial Scanner Mounted on Cell Wall 
• 
APPENDIX

\section{CONCEPTUAL DESIGN DRAWINGS}

This appendix consists of the five scope drawings listed below.

1. Conceptual drawing of pin guide clamp

2. Conceptual design of collimator

3. Detector arrangement and detector holder

4. Automated calibration source holder

5. Operating corridor arrangement 


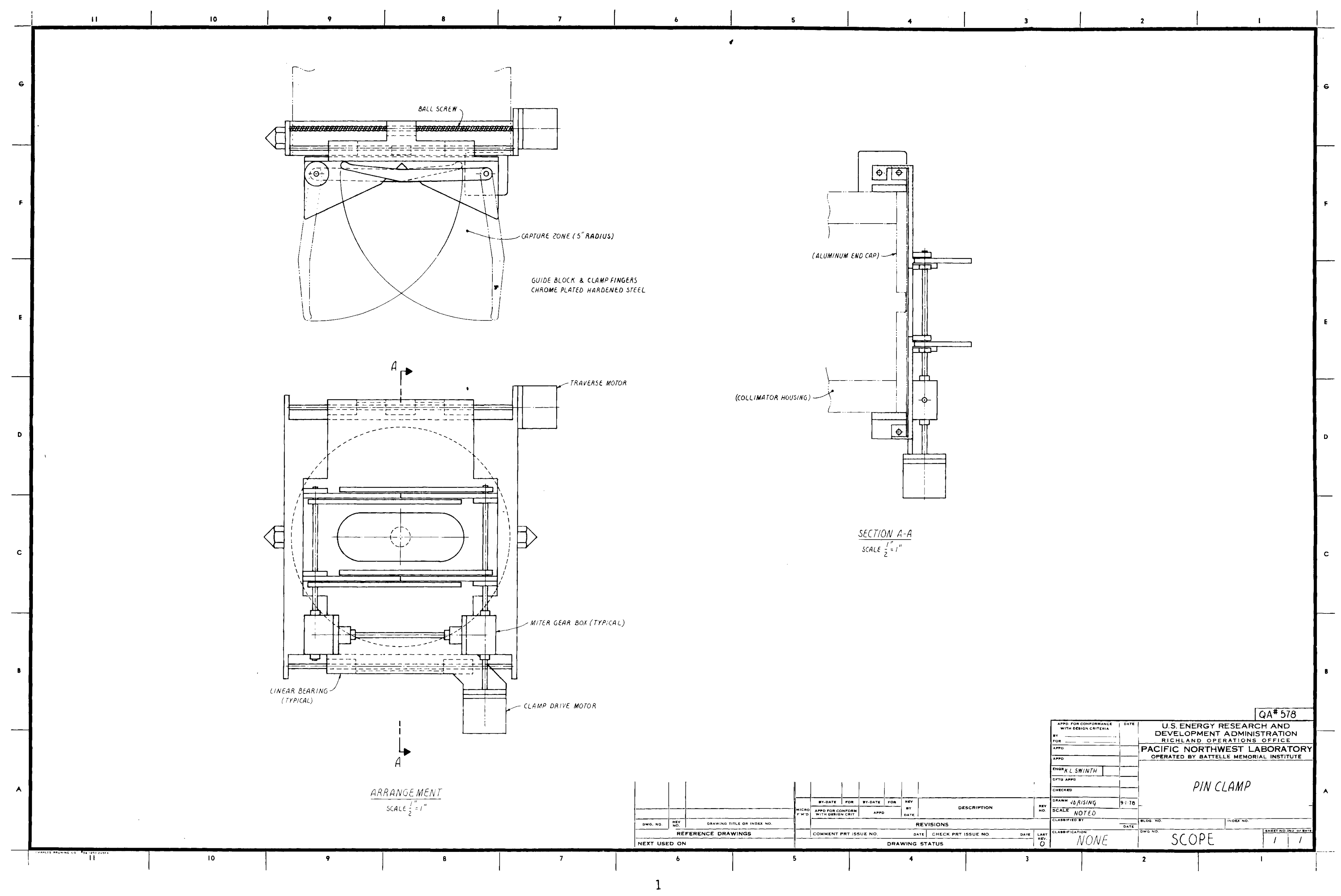




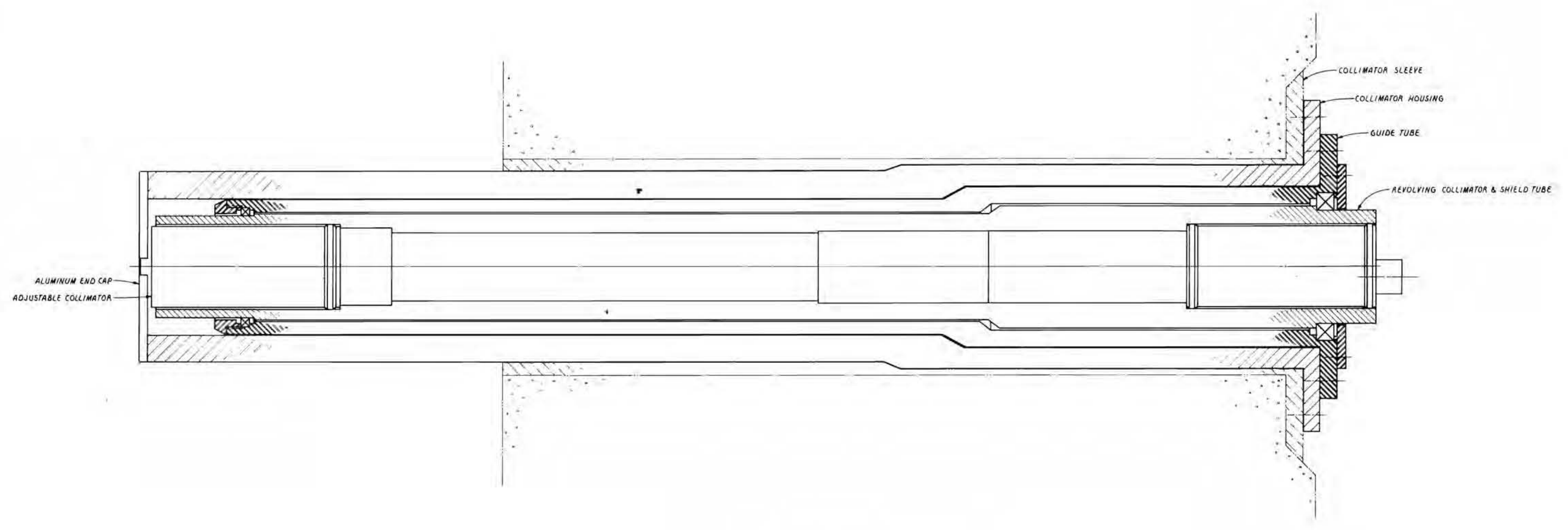

COLLIMATOR ARRANGEMENT

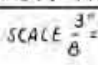

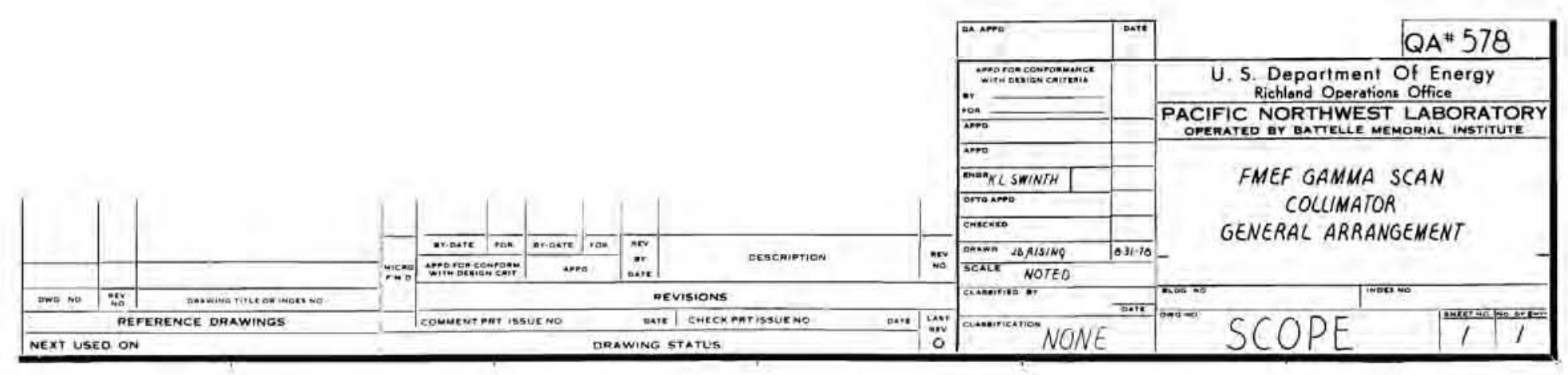




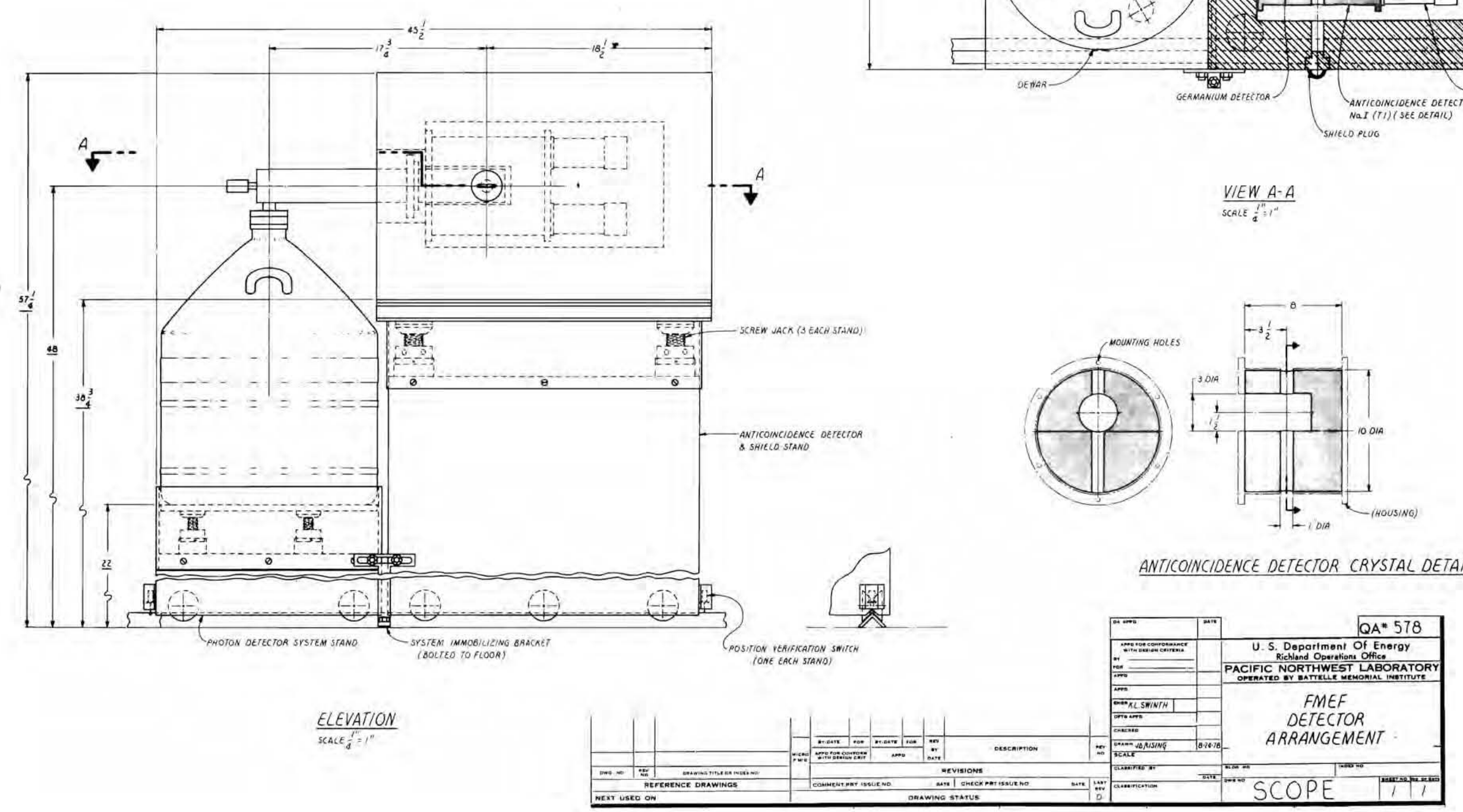



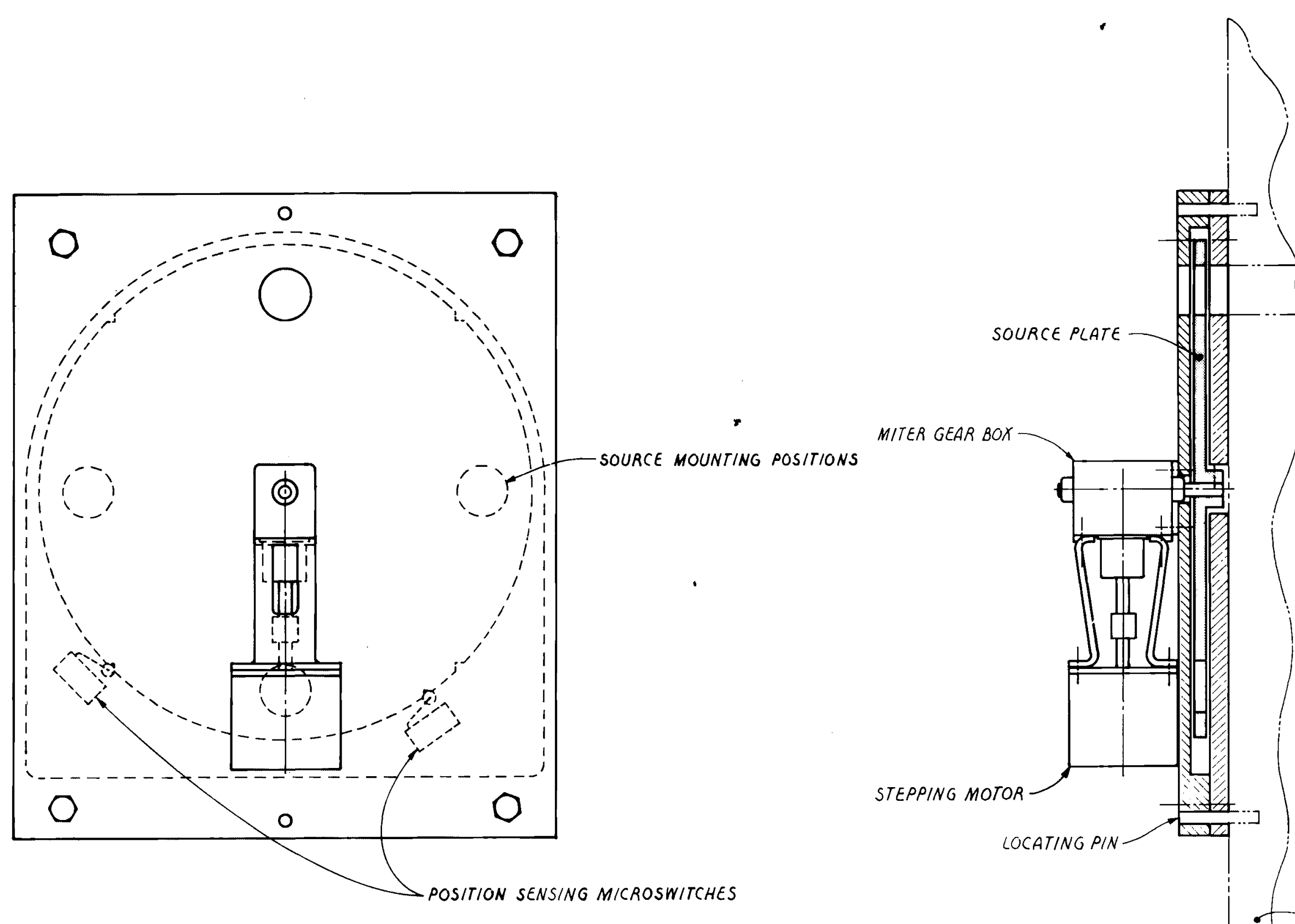

\section{ARRANGEMENT \\ $\operatorname{SCACE} \frac{l^{\prime \prime}}{2}=l^{\prime \prime}$}

$Q A^{*} 578$

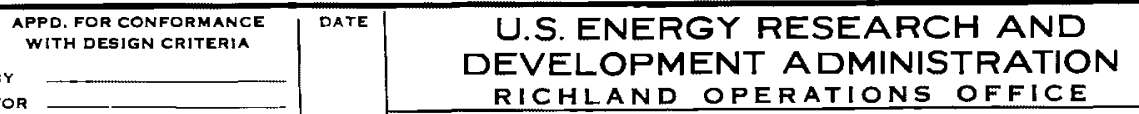
$=\frac{\text { RICHLAND OPERATIONS OFFICE }}{\text { PACIFIC NORTHWEST LABORATORY }}$ APPD -1 OPERATED BY BATTELLE MEMORIAL INSTITUTE

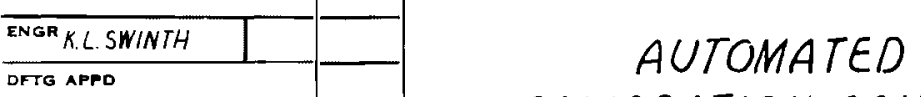
CALIBRATION SOURCE

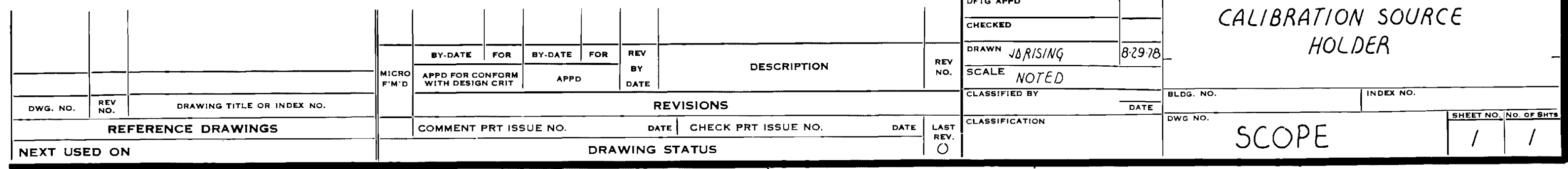




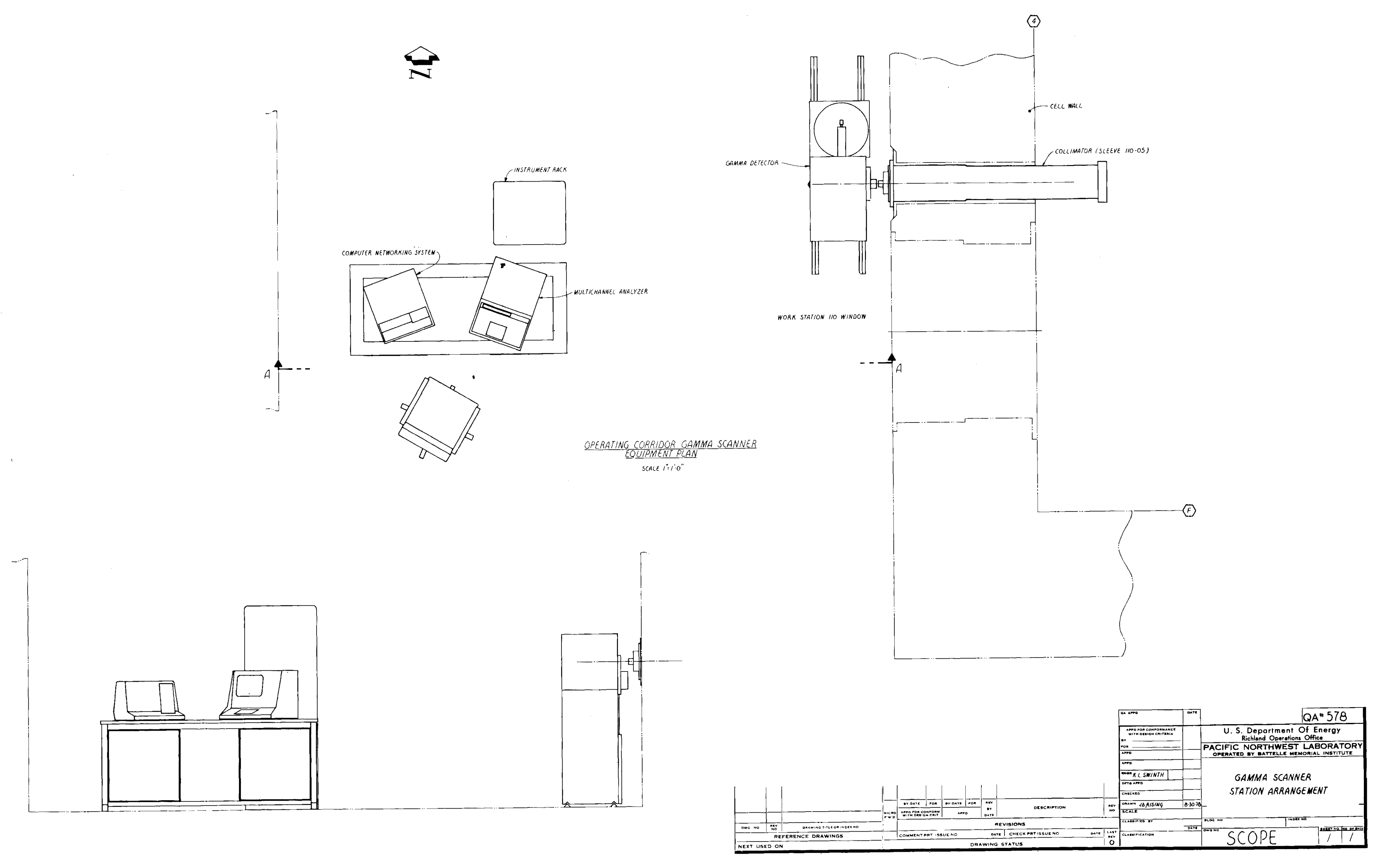




\section{Distribution}

No. of

Copies

OFFSITE

27 Technical Information Center

A. A. Churm

DOE Chicago Patent Group

9800 South Cass Avenue

Argonne, IL 60439

ONSITE

DOE Richland Operations Office

H. E. Ransom

21 Hanford Engineering Development Laboratory

J. W. Hess (8)

J. E. Tobin

R. A. Karnesby

J. W. Weber

D. T. Johnson

R. A. Daubert

G. B. Francen

G. A. Worth

R. Leggett

FMEF Central Files (2)

14 Pacific Northwest Laboratory

K. L. Swinth

(4)

W. J. Coleman

A. M. Sutey

C. Hann

Publishing Coordination (2)

Technical Information $\mathrm{JO}$ (5) 
